\title{
Adaptation to bipolar disorder and perceived risk to children: a survey of parents with bipolar disorder
}

\author{
Holly L Peay ${ }^{1 *}$, Donald L Rosenstein ${ }^{2}$ and Barbara B Biesecker ${ }^{1}$
}

\begin{abstract}
Background: Bipolar disorder (BPD) is a common condition associated with significant morbidity and reduced quality of life. In addition to challenges caused by their mood symptoms, parents affected with BPD harbor concerns about the mental health of their children. Among adult parents who perceive themselves to have BPD, this study aims to examine participants' coping methods; identify predictors of adaptation; assess parental perceptions of risks for mood disorders among their children; and describe the relationships among illness appraisals, coping, adaptation to one's own illness, and perceived risk to one's children.
\end{abstract}

Methods: Parents who self-identified as having BPD completed a web-based survey that assessed dispositional optimism, coping, perceived illness severity, perceived etiology of BPD, perceived risk to offspring, and adaptation to BPD. Participants had at least one unaffected child who was 30 years of age or below.

Results: 266 parents were included in the analysis. 87\% of parents endorsed a "somewhat greater" or "much greater" risk for mood disorders in one's child(ren) than someone without a family history. Endorsing a genetic/familial etiology to BPD was positively correlated with perceived risk for mood disorders in children $\left(r_{s}=.3\right.$, $p<0.01)$ and active coping with $\operatorname{BDP}(r=.2, p<0.01)$. Increased active coping $(\beta=0.4, p<0.001)$ and dispositional optimism ( $\beta=0.3, p<0.001)$ were positively associated with better adaptation, while using denial coping was negatively associated with adaptation $(\beta=-0.3, p<0.001)$. The variables explained $55.2 \%$ of the variance in adaptation ( $F=73.2, p<0.001$ ). Coping mediated the effect of perceived illness severity on adaptation.

Conclusions: These data inform studies of interventions that extend beyond symptom management and aim to improve the psychological wellbeing of parents with BPD. Interventions targeted at illness perceptions and those aimed at enhancing coping should be studied for positive effects on adaptation. Parents with BPD may benefit from genetic counseling to promote active coping with their condition, and manage worry about perceived risk to their children.

Keywords: Bipolar disorder, Adaptation, Quality of life, Genetic, Risk perception

\section{Background}

Bipolar disorder (BPD) represents a group of common, disabling conditions of mood dysregulation. The improved ability to control overt illness symptoms through psychopharmacological and psychosocial treatments, as highlighted in the Systematic Treatment Enhancement Program for Bipolar Disorder (STEP-BD) study [1], has afforded new

\footnotetext{
* Correspondence: hpeay@mail.nih.gov

'Social and Behavioral Research Branch, National Human Genome Research Institute NHGRI, Building 31 Room B1B36 31 Center Drive MSC 2073, Bethesda, MD 20892, USA

Full list of author information is available at the end of the article
}

opportunities for people with mental illness. However, studies suggest that functional and psychological wellbeing of individuals with bipolar disorders is not consistently predicted by symptom severity $[2,3]$. As evidence for the management of BPD symptoms improves, it is important to broaden our understanding of factors that contribute to psychological well-being (subjective assessments of life quality, including emotional reactions and cognitive judgments), beyond overt symptoms and predictors of symptom exacerbation and remission.

\section{Biomed Central}

(c) 2013 Peay et al.; licensee BioMed Central Ltd. This is an open access article distributed under the terms of the Creative Commons Attribution License (http://creativecommons.org/licenses/by/2.0), which permits unrestricted use, distribution, and reproduction in any medium, provided the original work is properly cited. 
A qualitative study of adults with BPD and their healthy siblings [4] reinforced the need to further explore the effects of BPD on the psychological well-being of affected individuals, at-risk children, and the family unit. Participants described distress around their perceived family vulnerability to mood disorders. Many described concerns about negative effects of BPD on their parenting abilities and the family, and concerns that these negative effects may increase the risk of mood disorders in offspring-perceptions supported by prior research $[5,6]$. Participants who perceived themselves to be better adapted to BPD seemed to better manage the effects of BPD on the family unit, and have lower concern about psychological outcomes in their children. Our qualitative study led to interest in evaluating, among parents with bipolar disorder, predictors of adaptation to BPD and whether there is a relationship among adaptation, perceived risk to children, and parental coping with risk to children.

\section{Well-being in bipolar disorder}

Most studies of well-being in BPD measure quality of life (QoL). QoL is an assessment, typically performed at one time period, of multiple domains used to represent global well-being. QoL assessments are typically applied to those managing a disease or condition. Individuals with BPD have lower QoL than individuals in the general population $[2,7,8]$. QoL has been shown to be significantly positively correlated with adaptation, which is another component of psychological wellbeing; however, they have been found to be associated with different predictor variables [9]. Adaptation is a measurable, positive outcome of coping with the stress of a health condition and consists of restored self-esteem, existential well-being, social reengagement, and coping efficacy [9].

Well-established predictors of psychological well-being include coping and personality traits, which exerting their influence through independent and interactive roles [10]. Efforts to prevent or diminish threat, harm, and loss, or to reduce associated distress are described as coping strategies [10]. Little is known about coping with BPD beyond coping with symptoms; coping in BPD has been primarily evaluated as a predictor of symptom response rather than psychological wellbeing $[11,12]$.

Existing studies of psychological well-being in BPD fall short in identifying patients' perceptions of their abilities to manage BPD. For example, there is limited data on the appraisals that engage use of coping strategies and whether they are effective in enhancing adaptation [13]. Studying contributors to adaptation to BPD, including illness perceptions and coping, broadens our understanding of the inter-relationship of these concepts and can inform the design of intervention studies aimed at improving psychological wellbeing.

\section{Concerns about mood disorders in children}

Stressors facing parents with BPD may include worries about risk of mood disorders in their children, and how to manage those risks [4]. A significant proportion of individuals affected with serious psychiatric disorders have concerns about their children's risks for psychiatric disorders [14-16]. These concerns are warranted by the high heritability of BPD, estimated at $85 \%$ [17], and a 20\%-30\% estimated lifetime risk for a mood disorder in a first-degree relative of an individual with BPD $[18,19]$. Affected individuals tend to appreciate the etiological complexity, attributing illness causation to a range of genetic and environmental factors $[4,20,21]$.

The negative impact of parental BPD on family functioning and increased risk to offspring [5,6], together with data showing that affected parents are aware of genetic and environmental avenues for increased risk to children [4], supports investigating the relationship between parental adaptation to their BPD and perceived risk to their children. Data about the factors that influence risk perception may inform genetic counseling and suggest whether interventions targeted at disorder adaptation may impact perception of risk to children.

Among adult parents who perceive themselves to have BPD the specific aims were to:

1. Examine participants' coping methods and test bivariate relationships with coping, anticipating the importance of coping as a predictor of adaptation [10];

2. Identify predictors of adaptation to BPD;

3. Assess parental perceptions of risks for mood disorders in their children; and

4. Describe the relationships among illness appraisals, coping, adaptation to one's own illness, and perceived risk to one's children.

We hypothesized that higher adaptation to bipolar disorder would be predicted by dispositional optimism, lower perceived illness severity, and coping type.

\section{Methods}

This cross-sectional survey was self-administered online. The survey was listed by mental health advocacy organizations (including National Alliance on Mental Illness, Bipolar World, Bipolar Significant Others, and Depression and Bipolar Support Alliance) and word-of-mouth recruiting. Adults who report as having 1) BPD and 2) at least one unaffected biological child aged 30 or younger were eligible to participate. Recruitment was limited to parents of children 30 years or younger because the average age at BPD onset is in the late 20s [18].

Our intent was to understand the perceptions of individuals who identify themselves as having BPD. Similar to the majority of cross-sectional surveys of disorder 
populations, especially online surveys, the accuracy of participant self-identification was assumed; i.e., the survey does not include a measure to evaluate mental health status. This approach is consistent with on-line surveys of many populations and offers the opportunity for greater understanding of the lived experiences of patients in a feasible manner.

This study was approved by the National Human Genome Research Institute's Institutional Review Board. Informed consent was presumed by the participants' willingness to complete the online survey.

\section{Measures}

Data include respondents' age, age at diagnosis, sex, ethnicity, marital status, state of residence, number of child (ren), and age of child(ren). For those with more than one child, we collected data about birth order and sex of the child they worried about the most, and included an openended question about why this child was associated with the most worry. The study was framed by the Transactional Theory of Stress and Coping [13].

\section{Predictor variables IIIness characteristics and perceptions}

The survey included one question each about whether the participant perceived him/herself as currently manic or currently depressed. The response options were "yes", "no", or "uncertain"; results were dichotomized to yes or no/uncertain. The survey also included a query about the participant's degree of confidence that $\mathrm{BPD}$ is the diagnosis that best explains his/her symptoms, scored on a 1-5 scale of "not at all" to "very much."

\section{Perceived illness severity (Brief Illness Perceptions Questionnaire)}

The Brief IPQ [22] measured self-assessed illness severity. The measure has previously been used in populations of individuals with mental illness $[23,24]$. The 8 items, on a scale of 0-9 anchored with extremes (e.g., "No effect at all" to "Severely affects my life"), were summed and higher scores indicate increased severity. In this sample, Cronbach's alpha was 0.7 .

\section{Perceived etiology of BPD}

Based on a past qualitative study and clinical experience, we developed a new measure of people's perceptions about "how bipolar disorder happens in families." Principle components analysis (PCA) on the 5-item Perceived Etiology Measure revealed a two-component solution that explained $77 \%$ of the variance. Factor 1 included genetic and familial items and factor 2, attributes and environment. The items from each factor were averaged, with higher scores indicating increased endorsement. Cronbach's alpha was 0.7 for factor 1 and 0.8 for factor 2. See Additional file 1 .

\section{Dispositional optimism (Life Orientation Test, LOT)}

The LOT [25] was used to measure participants' dispositional optimism. We were unable to identify a study that used this measure in a population with bipolar disorder; however, it is frequently evaluated as a moderator of psychological impairment in a target population (e.g., Thomas and colleagues, 2011) [26]. The 8 scored items (scale of 0-4, "strongly disagree" to "strongly agree") were summed, with higher scores indicating greater optimism. Cronbach's alpha was 0.9 .

\section{Coping with BPD}

We used the 28-item Brief COPE [27] to assess coping with BPD. This measure has previously been used in a population with mental illness [28].

PCA identified the relevant coping domains in this population: a two-component solution using 16 items that explained $48 \%$ of the variance. Component 1, "active/ social support coping," loaded to 11 active coping/social support items and had a Cronbach's alpha of 0.9. Component 2, "self-blame/denial coping," loaded to 5 selfblame/denial items and had a Cronbach's alpha of 0.7 . For each factor, the items (on a 1-4 scale, "I usually don't do this at all" to "I usually do this a lot") were summed and averaged, with higher scores indicating increased use of the coping type.

\section{Outcome variables}

\section{Psychological adaptation scale (PAS)}

Adaptation to bipolar disorder was measured using the PAS, comprising self-esteem, social integration, spiritual/ existential meaning, and coping efficacy domains [9]. The 20 items (on a 1-5 scale, "not at all" to "very much") were averaged, with higher scores indicating increased adaptation. This measure has not been used in a population with mental illness. In other populations, alpha scores of reliability have ranged from 0.83 to 0.97 [9] in previous studies. Cronbach's alpha in this sample was 0.9 .

\section{Perceived risk to children}

Perceived risk was assessed with the following item: "Compared to a child who does not have anyone in his/ her family with a mood disorder, in my opinion MY child has a chance to have a mood disorder," with five response options ranging from 'much smaller' to 'much greater'. Participants with more than one child were prompted to answer based on the child they worried about the most.

\section{Statistical analysis}

Data were analyzed using the statistical software SPSS Statistics 17.0. Age of participant, age of child, time since diagnosis, number of children, confidence in diagnosis and self-report of current mania and current depression 
were defined as potential confounders. Bivariate associations between predictor variables, confounders, adaptation and perceived risk to children were examined using Pearson's and Spearman's correlations, respectively. Linear regression was used to assess the relationship between predictor variables and adaptation, controlling for confounders. We entered into the regression analysis all predictor variables with $\mathrm{p}<0.25$, then removed one variable at a time until only those with $\mathrm{p}$ values of $<0.05$ remained. We then added one potential confounder at a time and include any time the $\beta$ if a predictor variable changes by more than $10 \%$. To evaluate a post-hoc hypothesis that coping mediated the effect of illness perceptions on adaptation, we tested for mediation effects by using a series of regression analyses, as described by Vos et al. [29].

\section{Results}

\section{Sample population}

Two hundred and sixty-six parents with BPD completed the online survey. Table 1 shows the participant characteristics; the majority being Caucasian, female, married, and with more than one child. Participants resided in 43 states from across the United States. Participants' ages were normally distributed. We did not collect any additional demographic data in this sample.

\section{Descriptive results}

Table 2 shows means and standard deviations for the predictor and outcome variables.

The Perceived Etiology of BPD measure showed a significantly higher endorsement of genetic/familial etiology than attribute/environment, $t(241)=18.5, \mathrm{p}<0.001$ (two tailed). Responses to an open-ended question about perceived causes of BPD were consistent with the measure; while the most common response related to genetics, many respondents referenced a combination of genetic and environmental risk factors.

\section{Aim 1: Coping}

Participants who coped using active efforts and social support were less likely to cope using self-blame and denial. Higher use of active/social support coping was correlated with higher dispositional optimism, no endorsement of current depression, and less severe perceptions of BPD. Higher self-blame/denial coping was correlated with lower dispositional optimism, endorsement of current depression or mania, and more severe perceptions of BPD. Those participants who endorsed a genetic etiology were more likely to use active efforts/ social support to cope.

A correlation matrix of key variables is presented in Table 3.
Table 1 Characteristics of study population

\begin{tabular}{|c|c|c|}
\hline Variable & & $\mathbf{N}(\%)$ \\
\hline \multirow[t]{2}{*}{ Sex } & Male & $32(16.3 \%)$ \\
\hline & Female & $164(83.7 \%)$ \\
\hline \multirow[t]{7}{*}{ Race (choose all that apply) } & White & $181(68.0 \%)$ \\
\hline & Black/African-American & $9(3.4 \%)$ \\
\hline & $\begin{array}{l}\text { Native American or } \\
\text { Alaskan Native }\end{array}$ & $4(1.5 \%)$ \\
\hline & Asian & $1(0.4 \%)$ \\
\hline & Hispanic or Latino & $9(3.4 \%)$ \\
\hline & Other & $4(1.5 \%)$ \\
\hline & No Race Chosen & $68(25.6 \%)$ \\
\hline \multirow[t]{6}{*}{ Age } & $18-25$ & $12(6.1 \%)$ \\
\hline & $26-35$ & $44(22.4 \%)$ \\
\hline & $36-45$ & $73(37.1 \%)$ \\
\hline & $46-55$ & $60(30.5 \%)$ \\
\hline & $56-65$ & $8(4.0 \%)$ \\
\hline & Over 65 & 0 \\
\hline \multirow[t]{4}{*}{ Marital status } & Married & 117 (59.7\%) \\
\hline & Separated or Divorced & $56(28.6 \%)$ \\
\hline & Never Married & $22(11.2 \%)$ \\
\hline & Widowed & $1(0.5 \%)$ \\
\hline \multirow[t]{6}{*}{ Time since diagnosis } & Less than 1 year & 29 (10.9\%) \\
\hline & $1-5$ years ago & $88(33.1 \%)$ \\
\hline & $6-10$ years ago & $67(25.2 \%)$ \\
\hline & $11-15$ years ago & $44(16.5 \%)$ \\
\hline & $16-20$ years ago & $23(8.6 \%)$ \\
\hline & More than 20 years ago & $15(5.6 \%)$ \\
\hline Number of States represented & & 43 \\
\hline
\end{tabular}

\section{Aim 2: Adaptation}

Parents with BPD had a mean adaptation score of 2.6 $(\mathrm{SD}=1.2)$, lower than scores found in eight studies of adaptation to other chronic illnesses, where it ranged from 2.7-4.2 (SD range 0.6-1.2) [9]. Multiple linear regression was used to assess the contributions of perceived

Table 2 Means and standard deviation of key variables

\begin{tabular}{lr}
\hline Predictor variable & Mean (SD) \\
\hline Dispositional optimism & $13.5(6.4)$ \\
Illness severity & $46.0(9.6)$ \\
Perceived etiology measure: genetic/familial component & $4.2(0.8)$ \\
Perceived etiology measure: attributes & $2.8(1.0)$ \\
Active/social coping & $2.9(0.7)$ \\
Self-Blame/denial coping & $2.3(0.7)$ \\
Adaptation & $2.6(1.0)$ \\
Perceived risk to child & $4.2(0.9)$ \\
\hline
\end{tabular}


Table 3 Correlation of key variables

\begin{tabular}{|c|c|c|c|c|c|c|c|c|c|c|}
\hline Item & 1 & 2 & 3 & 4 & 5 & 6 & 7 & 8 & 9 & 10 \\
\hline 1. Adaptation & - & $-.50^{* *}$ & $.57^{* *}$ & $.56^{* *}$ & $-.48^{* *}$ & .02 & .13 & $.24^{* *}$ & $.26^{* *}$ & $.15^{*}$ \\
\hline 2. Self-Blame/denial coping & & - & $-.20^{* *}$ & $-.37^{* *}$ & $.51^{* *}$ & -.04 & $-.22^{* *}$ & $-.19^{* *}$ & -.13 & $-.15^{*}$ \\
\hline 3. Active/social support coping & & & - & $.39^{* *}$ & $-.28^{* *}$ & .05 & .01 & $.28^{* *}$ & $.28^{* *}$ & $.17^{*}$ \\
\hline 4. Dispositional optimism (LOT) & & & & - & $-.46^{* *}$ & -.06 & .08 & $.47^{* *}$ & .07 & $.13^{*}$ \\
\hline 5. Self-assessed illness severity (Brief IPQ) & & & & & - & .03 & $-.27^{* *}$ & $-.27^{* *}$ & .06 & $-.17^{*}$ \\
\hline 6. Parent perception of risk for mood disorder in children & & & & & & - & .02 & .05 & .13 & $.31^{* *}$ \\
\hline 7. Currently manic (self report) & & & & & & & - & -.05 & -.05 & .12 \\
\hline 8. Currently depressed (self report) & & & & & & & & - & $.26^{* *}$ & $.18^{* *}$ \\
\hline 9. Confidence in diagnosis & & & & & & & & & - & $.27^{* *}$ \\
\hline 10. Perceived etiology measure: genetic/familial component & & & & & & & & & & - \\
\hline
\end{tabular}

${ }^{* *}$ Correlation is significant at the 0.01 level (2-tailed).

*Correlation is significant at the 0.05 level (2-tailed).

illness severity, coping, dispositional optimism, depression, and participant demographics to variation in adaptation. The final model showed that active/social support coping $(\beta=0.4, p<0.001)$ and dispositional optimism $(\beta=0.3$, $p<0.001)$ were significantly associated with adaptation, and self-blame/denial coping $(\beta=-0.3, p<0.001)$ exhibited a negative association; together the variables explained $55.2 \%$ of the variance $(\mathrm{F}=73.2, \mathrm{p}<0.001)$. The two items measuring participants' perceptions of their current mania and depression were not significant in the multivariate analysis.

Self-assessed illness severity (Brief IPQ) was not significant in the final regression model. Given the strong correlation between the Brief IPQ score and adaptation, we evaluated for a mediating effect of coping on the relationship between illness severity and adaptation (see Table 4) using a series of regression analyses. The results of the mediation analysis support a mediation role for active/social support coping and self-blame/denial coping on the relationship between illness severity and adaptation.

\section{Aims 3 and 4: Perceived risk to children}

Eighty-seven percent of participants endorsed a "somewhat greater" or "much greater" risk for mood disorders in one's child(ren) than someone without a family history-see Figure 1. The risk for a mood disorder in the participants'

\section{Table 4 Results of mediation analyses}

\begin{tabular}{lccc}
\hline & \multicolumn{2}{c}{ Beta } & p-value \\
\hline Illness severity (Brief IPQ) & \multicolumn{2}{c}{-0.48} & $\mathrm{p}<0.001$ \\
regressed on adaptation & & & \\
COPE domain regressed & Cope 1* & Cope 2^ & $\mathrm{p}<0.001$ \\
on adaptation & 0.57 & -0.50 & \\
Brief IPQ and COPE domain & Cope 1* & Cope 2^ & $\mathrm{p}<0.001$ \\
regressed on adaptation & -0.35 & -0.30 & \\
\hline
\end{tabular}

*Cope domain $1=$ active/social support.

$\wedge$ Cope domain 2 = self-blame/denial. offspring is expected to be greater than population risk, especially given the strong family histories reported (data not included). Higher perceived risk was correlated with endorsing a genetic etiology $(\mathrm{rho}=0.31, p<0.001)$. No confounders were significantly correlated with perceived risk, including child's age, sex of child, birth order of child, confidence in diagnosis, and endorsement of mania or depression. In addition, participants' dispositional optimism, perceived illness severity, coping and adaptation were not significantly correlated with perceived risk.

Parents with more than one child were asked which child they worried about the most. We also asked an open-ended question: "Why do you worry about this child the most?" The analyses of these responses revealed four themes related to increased parental concerns:

- Similarities of the child to the affected parent (i.e., in personality and behavior);

- Concerning mood states in the child (e.g., low mood, mood swings, anxiety, and attention deficit hyperactivity disorder);

- Adverse personality traits in the child (e.g., hypersensitive/emotional, angry, and poor social skills); and

- Exposure to parent's symptoms or poor home environment resulting from parent's illness, perceived as particularly burdensome for this child.

\section{Discussion}

Health care providers have opportunities to improve psychological well-being for adults with BPD. Illness perceptions and coping are potential targets for nonpharmacological interventions aimed to improving overall well-being, even in individuals with BPD whose symptoms are well controlled. We identified aspects of coping that facilitate, and aspects that hinder, adaptation. Overall, respondents were only moderately well-adapted. 


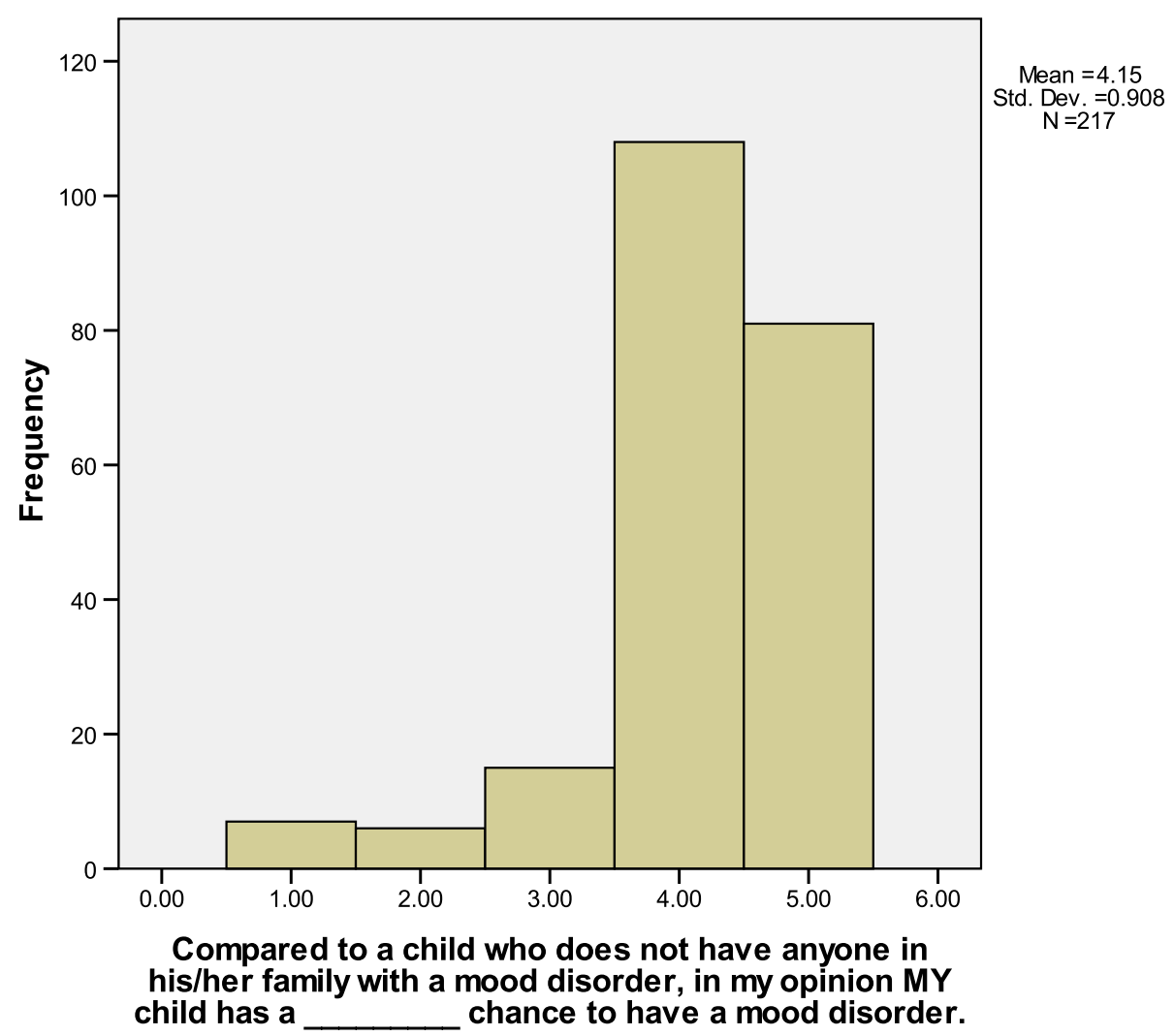

Figure 1 Parents' perceived higher risk to their children compared to the population risk. $1.00=$ Much smaller; $2.00=$ Somewhat smaller; 3.00 = Equal; $4.00=$ Somewhat greater; $5.00=$ Much greater .

Consistent with our results, coping is typically conceptualized as comprising two domains-an active, positive domain and an avoidance-oriented domain. Using the BRIEF Cope measure, Meyer and colleagues [28] described similar domains in a small hospitalized population of predominantly schizophrenic patients. The relative benefits of active coping and disadvantages of avoidance coping on psychological well-being have been described in many disease populations [10]. We found that coping mediates the effect of appraisal of illness severity on adaption. In the predominantly schizophrenic population, Meyer and colleagues identified a mediating effect of measured illness severity on "adaptive" (active/supportseeking) coping, but not on "maladaptive" coping [28].

Dispositional optimism predicted coping and adaptation. A number of studies have reported a positive relationship between dispositional optimism and the use of adaptive coping strategies [30,31]. Similar to other studies $[30,32]$ increased dispositional optimism is negatively associated with depressive symptoms, though measures of dispositional optimism are intended to measure a stable trait that is independent of mood state. Given the importance of dispositional optimism in adaptation among this sample-regardless of whether it is a stable trait or one that is influenced by the underlying pathophysiology/symptomatology of BPD-it is important to take into consideration when targeting patient interventions.

This study informs the understanding of the relationship between parents' own illness perceptions and adaptation, and how they perceive their children's risk of developing mood disorders. These novel findings have important implications for a holistic treatment approach in an era of increased knowledge about the etiology and pathophysiology of bipolar disorder. Appraisals of illness severity, current mood state, coping, and adaptation were not correlated with perceived risk to children, suggesting that regardless of the state of management of their own BPD, they remain aware of the risk to their children. We may have selected for a sample of parents keenly concerned about risk to their children. Among them we found little evidence of minimizing or denying risk. Data from open-ended questions suggest that parents appraise risk based on reasonable characteristics (i.e., child's mood and personality traits, similarity to affected parent, and adverse home environment based on parent's illness). Future research may contribute to a more complete understanding of predictors of risk perception.

Limitations of this study include the use of a sample with self-reported bipolar disorder and a likelihood of 
selection bias for participants functioning well enough to complete the survey and interested in the research question. Similar to most survey populations, the sample lacks racial diversity and includes more females than males; data is not available on education or economic status. These biases limit generalisability to the population of parents with BPD. The survey did not include a characterization of illness course, which may have moderated participants' responses. A response rate is not available because the total number of individuals who had access to the web link but chose not to participate is unknown. Keeping in mind these limitations, our findings represent an important start to understanding the experiences of adults with BPD and their impact on their psychological well-being.

\section{Conclusions}

This study suggests the need for intervention studies to evaluate the effects of enhancing active/social support coping and minimizing self-blame/denial coping on adaptation. Faced with limited health care resources, interventions might best be targeted towards those with less optimism or greater depressive symptoms. Further studies of the role of illness appraisals in adaption to BPD are needed; such studies might explore whether Coping Effectiveness Training (CET), an evidence-based intervention aimed at helping participants identify areas of control and maximize active coping in those areas [33], might enhance the relationship between appraisals and coping.

The positive relationship between endorsing a genetic/ familial etiology and both active/social coping and risk perception reinforces the potential utility of genetic counseling in this population. Genetic counseling that refines clients' understanding of BPD etiology and related family risk may help patients manage uncertainty [34] and worry, and facilitate coping and adaptation.

\section{Additional file}

Additional file 1: Perceived Etiology of BPD Measure.

\section{Competing interests}

The authors declare that they have no competing interests.

\section{Authors' contributions}

HLP and BBB designed the study with input from DLR. HLP collected the data and conducted the statistical analysis. All authors read and approved the manuscript.

\section{Acknowledgements}

This work was supported by the Intramural Research Program of the National Human Genome Research Institute, National Institutes of Health. The authors have no conflicts to disclose.

Cris Price (Abt Associates) provided valuable input into the statistical analysis. We would like to express our gratitude to Drs. Phillip Shaw, Pietro de Rossi, and Bettina Meiser for valuable input on a draft of the manuscript. We thank the parents who were willing to share their perceptions and experiences in this survey.

\section{Author details}

'Social and Behavioral Research Branch, National Human Genome Research Institute NHGRI, Building 31 Room B1B36 31 Center Drive MSC 2073, Bethesda, MD 20892, USA. ${ }^{2}$ Department of Psychiatry and Comprehensive Cancer Support Program, University of North Carolina at Chapel Hill, Physicians Office Building, Room 3134, Chapel Hill, NC 27599, USA.

Received: 16 November 2012 Accepted: 12 November 2013 Published: 2 December 2013

\section{References}

1. Bowden CL, Perlis RH, Thase ME, Ketter TA, Ostacher MM, Calabrese JR, Reilly-Harrington NA, Gonzalez JM, Singh V, Nierenberg AA, et al: Aims and results of the NIMH systematic treatment enhancement program for bipolar disorder (STEP-BD). CNS Neurosci Ther 2011, 18(3):243-249.

2. Michalak EE, Murray G, Young AH, Lam RW: Burden of bipolar depression: impact of disorder and medications on quality of life. CNS Drugs 2008, 22(5):389-406

3. Suto M, Murray G, Hale S, Amari E, Michalak EE: What works for people with bipolar disorder? Tips from the experts. J Affect Disord 2010, 124(1-2):76-84.

4. Peay HL, Hooker GW, Kassem L, Biesecker BB: Family risk and related education and counseling needs: perceptions of adults with bipolar disorder and siblings of adults with bipolar disorder. Am J Med Genet A 2009, 149A(3):364-371.

5. Du Rocher Schuldich TD, Youngstrom EA, Calabrese JR, Findling RL: The role of family functioning in bipolar disorder in families. J Abnorm Child Psychol 2008, 36(6):849-863.

6. Hodgins S, Faucher B, Zarac A, Ellenbogen M: Children of parents with bipolar disorder: a population at high risk for major affective disorders. Child Adolesc Psychiatr Clin N Am 2002, 11(3):533-553.

7. Guan B, Deng Y, Cohen P, Chen H: Relative impact of Axis I mental disorders on quality of life among adults in the community. J Affect Disord 2011, 131(1-3):293-298.

8. Watson HJ, Swan A, Nathan PR: Psychiatric diagnosis and quality of life: the additional burden of psychiatric comorbidity. Compr Psychiatry 2011, 52(3):265-272

9. Biesecker BB, Erby L, Woolford S, Adcock JY, Cohen J, Lamb A, Lewis K, Truitt M, Turriff A, Reeve BB: Development and validation of the psychological adaptation scale (PAS): use in six studies of adaptation to a health condition or risk. Patient Educ Couns 2013, 93(2):248-254.

10. Carver CS, Connor-Smith J: Personality and coping. Annu Rev Psychol 2010, 61:679-704

11. Pavlickova H, Varese F, Smith A, Myin-Germeys I, Turnbull OH, Emsley R, Bentall RP: The dynamics of mood and coping in bipolar disorder: longitudinal investigations of the inter-relationship between affect, self-esteem and response styles. PLoS One 2013, 8(4):e62514.

12. Lam D, Wong G, Sham P: Prodromes, coping strategies, and course of illness in bipolar affective disorder-a naturalistic study. Psychol Med 2001, 31(8):1397-1402.

13. Lazarus RS, Folkman S: Stress, appraisal, and coping. New York: Springer Publishing Company; 1984.

14. Trippitelli C, Jamison K, Folstein M, Bartko J, DePaulo J: Pilot study on patients' and spouses' attitudes toward potential genetic testing for bipolar disorder. Am J Psychiatry 1998, 155(7):899-904.

15. Quaid KA, Aschen SR, Smiley CL, I NJ: Perceived genetic risks for bipolar disorder in a patient population: an exploratory study. J Genet Counsel 2001, 10:41-51.

16. Austin J, Smith G, Honer W: The genomic era and perceptions of psychotic disorders: genetic risk estimation, associations with reproductive decisions and views about predictive testing. Am J Med Genet B Neuropsychiatr Genet 2006, 141(8):926-928.

17. Bienvenu OJ, Davydow DS, Kendler KS: Psychiatric 'diseases' versus behavioral disorders and degree of genetic influence. Psychol Med 2011, 41(1):33-40.

18. Goodwin F, Jamison K: Manic depressive illness. London: Oxford Press; 1990

19. Nurnberger JL, Berrettini W: Psychiatric genetics. London: Chapman and Hall; 1998.

20. Targum S, Dibble E, Davenport Y, Gershon E: The family attitudes questionnaire: patients' and spouses' views of bipolar illness. Arch Gen Psychiatry 1981, 38(5):562-568. 
21. Meiser B, Mitchell P, Kasparian N, Strong K, Simpson J, Mireskandari S, Tabassum L, Schofield P: Attitudes towards childbearing, causal attributions for bipolar disorder and psychological distress: a study of families with multiple cases of bipolar disorder. Psychol Med 2007, 37(11):1601-1611.

22. Broadbent $\mathrm{E}$, Petrie $\mathrm{KJ}$, Main J, Weinman J: The brief illness perception questionnaire. J Psychosom Res 2006, 60(6):631-637.

23. Broadbent E, Kydd R, Sanders D, Vanderpyl J: Unmet needs and treatment seeking in high users of mental health services: role of illness perceptions. Aust N Z J Psychiatry 2008, 42(2):147-153.

24. Baines T, Wittkowski A: A systematic review of the literature exploring illness perceptions in mental health utilising the self-regulation model. J Clin Psychol Med Settings 2012, 20(3):263-274.

25. Scheier MF, Carver CS: Optimism, coping, and health: assessment and implications of generalized outcome expectancies. Health Psychol 1985, 4(3):219-247.

26. Thomas JL, Britt TW, Odle-Dusseau H, Bliese PD: Dispositional optimism buffers combat veterans from the negative effects of warzone stress on mental health symptoms and work impairment. J Clin Psychol 2011, 67(9):866-880

27. Carver CS: You want to measure coping but your protocol's too long: consider the brief COPE. Int J Behav Med 1997, 4(1):92-100

28. Meyer B: Coping with severe mental illness: relations of the brief COPE with symptoms, functioning, and well-being. J Psychopathol Behav 2001, 23(4):265-277

29. Vos J, Gomez-Garcia E, Oosterwijk JC, Menko FH, Stoel RD, van Asperen CJ, Jansen AM, Stiggelbout AM, Tibben A: Opening the psychological black box in genetic counseling: the psychological impact of DNA testing is predicted by the counselees' perception, the medical impact by the pathogenic or uninformative BRCA1/2-result. Psychooncology 2010, 21(1):29-42.

30. Wilhelm K, Wedgwood L, Parker G, Geerligs L, Hadzi-Pavlovic D: Predicting mental health and well-being in adulthood. J Nerv Ment Dis 2010, 198(2):85-90.

31. Tomakowsky J, Lumley MA, Markowitz N, Frank C: Optimistic explanatory style and dispositional optimism in HIV-infected men. J Psychosom Res 2001, 51(4):577-587.

32. Glaesmer $H$, Rief W, Martin A, Mewes R, Brähler E, Zenger M, Hinz A: Psychometric properties and population-based norms of the life orientation test revised (LOT-R). Br J Health Psychol 2011, 17(2):432-445.

33. Chesney MA, Chambers DB, Taylor JM, Johnson LM, Folkman S: Coping effectiveness training for men living with HIV: results from a randomized clinical trial testing a group-based intervention. Psychosom Med 2003, 65(6):1038-1046.

34. Hippman C, Lohn Z, Ringrose A, Inglis A, Cheek J, Austin JC: "Nothing is absolute in life": understanding uncertainty in the contex of psychiatric genetic counseling from the perspective of those with serious mental illness. J Genet Couns 2013, 22(5):625-632.

doi:10.1186/1471-244X-13-327

Cite this article as: Peay et al:: Adaptation to bipolar disorder and perceived risk to children: a survey of parents with bipolar disorder. BMC Psychiatry 2013 13:327.

\section{Submit your next manuscript to BioMed Central and take full advantage of:}

- Convenient online submission

- Thorough peer review

- No space constraints or color figure charges

- Immediate publication on acceptance

- Inclusion in PubMed, CAS, Scopus and Google Scholar

- Research which is freely available for redistribution 